\title{
Will the Future of Electric Vehicles be Powered by Accumulators or Hydrogen PEM Fuel Cells?
}

\section{O. Savadogo}

Director of the Laboratory on New Materials for Energy and Electrochemistry,

Department of Chemical Engineering,

Polytechnique Montreal

Corresponding Author Email: osavadogo@polymtl.ca

Received: October-26-2020, Accepted: November-29-2020, https://doi.org/10.14447/jnmes.v23i4.a01

\author{
Abbreviations \\ FEV: Fully Electric Vehicle \\ BEV: Battery Electric Vehicle \\ FCEV: Fuel Cell Electric Vehicle \\ ICE: Internal Combustion Engine \\ HEV: Non-Plug-In Hybrid Electric Vehicles \\ PHEV: Plug-In Hybrid Electric Vehicle
}

\section{CONTEXT}

In 1900, there were around 2,370 vehicles in use in New York, Chicago and Boston, 800 of which were $100 \%$ electric, 400 were running on gasoline and the remainder had steam engines. The gasoline vehicle prevailed over the others in terms of cost, infrastructure availability and convenience.

In 2010, there were 17,000 electric vehicles in use worldwide and, in 2019, there were 7.2 to 7.9 million of which 47\% were in China. More than 2 million were sold in 2019.

Nowadays, the issue of energy transition is crucial at the global level in order to ensure a better common future and it is becoming paramount that the issue of transportation, which accounts for $28.7 \%$ of greenhouse gas emissions according to the IEA (International Energy Agency) forecast for 2040, be solved by using “cleaner" energy sources.

In this context, comparisons between fully electric vehicles (FEVs), which are either vehicles using rechargeable batteries or accumulators (BEVs), and fuel cell electric vehicles (FCEVs) are numerous including economic considerations, available infrastructure, performance or market availability. But it is also important to consider a context where they would both replace internal combustion vehicles (ICEs). The other types of vehicles that preceded BEVs (Battery electric vehicles) are non-plug-in hybrid electric vehicles (HEVs) and plug-in hybrid electric vehicles (PHEVs). This paper provides an overview of the different types of electric vehicles on the market and the prospects for fully electric vehicles (FEVs) that use rechargeable batteries or accumulators (BEVs) and fuel cell electric vehicles (FCEVs).

\section{DEFINITIONS OF DIFFERENT TYPES OF ELECTRIC VEHICLES}

For HEVs (non-plug-in hybrid electric vehicles) ranging from micro to high hybridization, the use of gasoline to produce internal combustion ensures the main range of the vehicle while the energy from the accumulator is generally less than $2 \mathrm{kWh}$. Therefore, it is back-up energy that reduces the consumption of gasoline (or diesel) by switching from electric to internal combustion and vice versa depending on the speed of the vehicle. The HEV's accumulator is recharged when the vehicle is in internal combustion mode or when brakes are applied.

PHEVs are plug-in electric vehicles that can be recharged using a grid or other decentralized renewable sources of energy such as PV (Photovoltaic) solar or wind. In the case of PHEVs, the disadvantage is that the vehicle has to bear the cost of two complete powertrains, one electric and one gasoline (or diesel). The energy available from the accumulator varies between 7 and $20 \mathrm{kWh}$, depending on the vehicle model, and offers a range of 16 to $85 \mathrm{~km}$. When depleted, the internal combustion engine is automatically used to ensure the vehicle's traction.

Some fully electric vehicles (FEVs) use rechargeable batteries (BEVs) while others use fuel cells (FCEVs).

Lithium-ion (Li-ion) batteries are currently the most widely used accumulator technology in electric vehicles. The negative electrodes of these accumulators are carbon- or graphite-based with a binding agent deposited on a copper current collector. Before they are used for vehicle traction, the batteries are charged in advance, a process by which lithium forms intercalation compounds in the carbon or graphite. When the accumulator is discharged, in order to ensure the vehicle's traction, these carbon or graphite electrodes release lithium ions from intercalation compounds. The resulting lithium ions 
pass through an electrolyte made from one or more organic solvents or a molten electrolyte that transports them to the positive terminal where they will be inserted. A similar reaction process occurs in the case of the lithium metalpolymer accumulator (Li-polymer) where the negative electrode is metallic lithium deposited, for example, on aluminum foil and a solid ionic conductive polymer membrane is used as an electrolyte. Although its energy density is significantly higher than that of a lithium-ion battery, the lithium metal-polymer technology is very little used for this application because of the technological challenges that still need to be overcome.

In both cases, the reaction product is this energy provided to the vehicle and heat is also produced. Positive electrodes are based on cobalt oxide, nickel oxide, manganese oxide, iron phosphate or their mixture. For example, combinations of nickel, manganese and cobalt oxides (NMC), nickel, cobalt, aluminum (NCA) or nickel, manganese, aluminum (NMA) are developed to decrease the amount of cobalt or eliminate it from the composition of positive electrodes. Some combinations are already on the market. These vehicles could also be equipped with electrochemical capacitors or with flywheels as backup energy systems to ensure start-up and acceleration. This would also help to optimize the use of the vehicle's energy.

FCEVs (Fuel cell electric vehicles) are powered by pure hydrogen and oxygen from the outside of the cell. These gases are consumed at two different electrodes inside the cell respectively. The solid polymer electrolyte membrane fuel cell (PEMFC) is the type of cell used for the propulsion of fuel cell electric vehicles (FCEVs). Hydrogen is pressurized in a tank (outside the fuel cell) at 350 or 700 bars and powers one side of the cell. The other side is powered by the air taken from the outside and purified while the vehicle is moving. Hydrogen is consumed at the negative electrode of the cell and oxygen of the air at the positive electrode. The two electrodes or terminals are separated inside by a solid proton exchange membrane that transports hydrogen ions to the positive terminal when the vehicle needs energy. These ions recombine with the ions from the oxygen reduction and the total reaction product is this energy provided to the electric vehicle and the pure water that comes out of the exhaust pipe and heat is also produced. FCEVs (Fuel cell electric vehicles) are also generally equipped with a rechargeable battery system of less than $2 \mathrm{kWh}$ to enable better optimization of energy use when needed. This battery system could be replaced by a system of electrochemical capacitor or a flywheel system to ensure startup and acceleration.

Unlike the FCEV (Fuel cell electric vehicles) system where water flows when the vehicle is being operated, with batteries, the reaction products remain inside the battery, so no exhaust pipes are needed.

\section{FULLY ELECTRIC VEHICLES (VEES)}

\subsection{Performance}

The well-to-wheel efficiency of ICE systems does not exceed $17 \%$. That of FCEVs (Fuel cell electric vehicles) is $25 \%$ to $35 \%$ while that of BEVs (Battery electric vehicles) ranges from 70 to $85 \%$. This means that FCEVs (Fuel cell electric vehicles) use 2 to 3 times more primary energy than BEVs (Battery electric vehicles) while ICEs use 4 to 5 times more than BEVs.

The volumetric energy density in FCEVs (Fuel cell electric vehicles) is more than $2000 \mathrm{Wh} /$ litre. That of ICEs is 1000 $\mathrm{Wh} /$ litre, while BEVs (Battery electric vehicles) that offer the best performance and use a lithium-ion rechargeable battery with cobalt oxide cathodes, for example, is about $400 \mathrm{Wh} /$ litre for most vehicles in use today.

The gravimetric or specific energy density is more than 1200 $\mathrm{Wh} / \mathrm{kg}$ for FCEVs (Fuel cell electric vehicles) and similar for ICEs and less than $300 \mathrm{Wh} / \mathrm{kg}$ for BEVs (Battery electric vehicle).

Comparisons of specific energy densities (Wh/ $\mathrm{kg}$ ) and specific power densities $(\mathrm{W} / \mathrm{kg})$ of each system shows that operation time of FCEVs (Fuel cell electric vehicles) is estimated at ten hours, while that of BEVs (Battery electric vehicles) is estimated to be between one to a few hours.

With $5 \mathrm{~kg}$ of hydrogen at a pressure of 700 bars, you can drive non-stop from Montreal to Toronto $(550 \mathrm{~km})$ with a mediumsized FCEV (Fuel cell electric vehicle) that seats five without stopping for fuel. Most internal combustion vehicles from this segment can give you the same performance. On the other hand, most BEVs of standard models from this category that are still on the road do not offer the same range, even if the technology is evolving.

The range of some BEVs (Battery electric vehicles) is related to the concentration of rechargeable batteries that takes up more space and increases the weight of the vehicle, which could reduce the number of seats available for passengers in certain high-end categories with a high operating range.

In cold climates or during the winter, the range of BEVs (Battery electric vehicles) is about $60 \%$ lower than what is indicated by the manufacturer. It functions better during the spring and fall.

The estimated cost of energy to operate vehicles in US\$ for a distance of $100 \mathrm{~km}$ is $\$ 6$ to $\$ 14$ for FCEVs (Fuel cell electric vehicles) depending on the cost of hydrogen at the pump; $\$ 2$ to $\$ 3$ for an average consumption of $15-20 \mathrm{kWh} / 100 \mathrm{~km}$ for BEVs (Battery electric vehicles). For gasoline or diesel vehicles (ICEs), it is $\$ 10$ (for a vehicle consuming $8 \mathrm{~L} / 100 \mathrm{~km}$ at $\$ 1.25 /$ litre).

With current technology, according to our simulations for distances of about $500 \mathrm{~km}$, BEVs and FCEVs (Fuel cell electric vehicles) seem to have the same operating costs. For greater distances, the use of FCEVS (Fuel cell electric vehicles) is significantly less expensive than that of BEVs (Battery electric vehicles). Also, for hauling freight on long distances, FCEVs (Fuel cell electric vehicles) have more advantages in terms of operating costs and the weight of the energy powertrain system.

With current technology, a fuel cell system will be at least two to three times lighter than the battery system and provide the same amount of power to the engine. This can increase the payload of FCEVs (Fuel cell electric vehicles) semi-trailer trucks by several tonnes compared to BEVs (Battery electric vehicles). 
The total number of charging stations for BEVs (Battery electric vehicles) worldwide was estimated at 1 million in 2019 for approximately 7.3 million individual chargers, while that of hydrogen stations for FCEVs (Fuel cell electric vehicles) is estimated at 432 , of which 330 are operational.

Semi-trailer trucks powered by fuel cells can be developed on a business model based on fleets of long-haul transport vehicles with a hydrogen station infrastructure every 400 or $500 \mathrm{~km}$.

The limited availability of hydrogen stations contributes to restricting the use of FCEVs (Fuel cell electric vehicles) or the limited number of FCEVs is not conducive to the development of hydrogen stations for this application.

In most cases, it takes at best 1 to 2 hours and significantly more hours to fully charge BEVs (Fuel cell electric vehicles) after the system is fully depleted, whereas filling up a FCEV with hydrogen at a station is usually done in less than 5 minutes for compact vehicles and about 25 minutes for semitrailer trucks.

The cumulative number of BEVs in 2019 worldwide was estimated to be between 7.2 and 7.9 million, while the number of FCEVs was about 71,000. The forecast for FCEVs worldwide is more than 235,000 by 2025 .

The International Energy Agency (IEA) stated in its 2020 report that the national targets for $100 \%$ deployment of BEVs (Battery electric vehicles), FCEVs, other HEVs and PHEVs or zero-emission vehicles are spread out between 2025 and 2050 for several countries and regions of the world including Norway (2025), United Kingdom (2035), Canada (2040), France (2040), the United States of America (2050), Germany (2050) and Japan (2050). The Province of Quebec has just announced that they will stop selling gasoline and diesel vehicles by 2030 .

In 2019, in most countries, BEVs (Battery electric vehicles) have energy systems with capacities ranging between 50 and $70 \mathrm{kWh}$. For example, in 2020, a standard intermediate vehicle with a $60-\mathrm{kWh}$ battery system weighing $435 \mathrm{~kg}$ claims a range of 360-400 km depending on the supplier.

Assessing a specific carbon footprint is still difficult, but the consensus we share with many researchers in the field, such as the US Union of Concerned Scientists, is that the carbon footprint of FCEVs (Fuel cell electric vehicles) and BEVs (Battery electric vehicles) are similar to the current technology of both types of EVs.

The standard cost of BEVs (Battery electric vehicles) is generally well under CA $\$ 50,000$ per unit for mid-range cars (this does not include high-end cars) while that of FCEVs (Fuel cell electric vehicles) can well significantly exceed CA $\$ 50,000$ per unit.

\subsection{Advantages and disadvantages of BEVs (Battery electric vehicles) and FCEVs (Fuel cell electric vehicles)}

The advantages of BEVs (Battery electric vehicles):
The energy cost of rechargeable batteries for the electric car is decreasing. It decreased from US $\$ 1,190 / \mathrm{kWh}$ in 2010 to US $\$ 160 / \mathrm{kWh}$ in 2019 . Parity with gasoline price is expected in 2022 with a price of $\$ 100 / \mathrm{kWh}$ for battery power and a gasoline cost that will not collapse. Using BEVs reduces local pollution including noise pollution. The operating cost of BEVs (Battery electric vehicles) is low compared to that of FCEVs (Fuel cell electric vehicles) or ICEs because charging $\mathrm{BEVs}$ (Battery electric vehicles) is significantly less expensive than filling up with gas or hydrogen (for now). The maintenance cost is low for FCEVs (Fuel cell electric vehicles) compared to ICEs. Incentives are available when purchasing VEEs. In Canada, depending on the province, this purchase incentive can be as high as CA $\$ 13,000$. For example, in Quebec a CA $\$ 8,000$ incentive is offered by the Quebec government and CA $\$ 5,000$ is offered by the Federal government. BEVs (Battery electric vehicles) with batteries approaching their end-of-life can be used as renewable energy storage systems such as solar PV (Photovoltaic) and wind.

The disadvantages of BEVs (Battery electric vehicles):

The Lithium-ion-based battery which, apart from lithium, also uses cobalt, manganese, nickel, aluminum, graphite, etc. is the main rechargeable battery usually used for BEVS and for other applications such as our cell phones or other mobile devices. The materials used in Li-ion-based rechargeable batteries for fully electric vehicles are also used in the manufacturing of high-performance metallurgical materials for various other industrial applications.

The environmental and human costs associated with extracting these metals remain significant. Also, processes require significant improvements in a sustainable development context. By 2030, it is expected that there will be 125 million electric vehicles on the roads worldwide, the majority of which will be BEVs. Achieving or exceeding this number will depend on the environmental policies supported in each country. Nevertheless, this figure shows the enormous pressure that will be made on the extraction of lithium, cobalt, graphite, manganese, nickel, etc. According to suppliers, a 60 $\mathrm{kWh}$ BEV will require approximately 30 to $48 \mathrm{~kg}$ of lithium carbonate $\left(\mathrm{Li}_{2} \mathrm{CO}_{3}\right)$ and 10 to $15 \mathrm{~kg}$ of cobalt if cobalt oxide (LCO) is used as a lithium insertion cathode electrode when the vehicle is being operated. Beyond the strategic issues related to the availability and supply of these materials for BEVs, which we will address in a future publication, their extraction can lead to pollution of water, soil and air or poisoning of communities at the local level. Another drawback is the lack of adequate lithium accumulator recycling technology. They are to be developed taking into account toxicity, high reactivity and flammability, which is also the case with lithium. Some recycling technologies currently used allow the recovery of high-value-added metals such as cobalt or, to some extent, manganese or nickel. The accumulator used in some BEVs can also contain up to $35 \%$ aluminum in the material fused or the cathode. Accumulators thus become interesting "urban" mineral reserves to be extracted through recycling.

\section{The benefits of FCEVs (Fuel cell electric vehicles):}

With full hydrogen, they have a much larger range (between 400 and over $650 \mathrm{~km}$ depending on the category and the manufacturer) than BEVs (Battery electric vehicles), while offering the same number of seats in a vehicle as ICEs. Unlike BEVs (Battery electric vehicles), FCEV's range is not really 
related to the volume or weight of the energy system. There is no greenhouse gas pollution when using these two types of electric vehicles, unless hydrogen is produced to power the fuel cell, if the electricity used to charge batteries is not carbon-neutral and if they do not emit particles or other pollutants too. These vehicles do not produce noise pollution with a driving performance identical to the ICEs.

\section{The disadvantages of FCEVs (Fuel cell electric vehicles):}

Taking into account the production and storage of hydrogen, they have a significantly lower overall efficiency than BEVs (Battery electric vehicles). Their operating costs are also significantly higher than BEVs (Battery electric vehicles). The materials (platinum and alloy materials of the platinum group) involved in the reactions of the fuel cell (FC) which supplies energy to the FCVE (Fuel cell electric vehicle) are rare and expensive (CA $\$ 40.85 /$ gram of platinum on August 17, 2020). A FCVE with $115 \mathrm{~kW}$ of power, with current technology, requires about 30 to 60 grams of platinum depending on the manufacturers and the type of vehicle. As a result, the cost of the fuel cell system currently represents $35-51 \%$ of the total cost of the vehicle depending on the model. The estimate of the world platinum reserve is 69,000 tonnes, but with future potential reserves to be discovered. Platinum is already widely used in several other activities: catalytic converter in the car industry (more than $41 \%$ of the platinum used in 2016), jewelry, fiberglass, fertilizers, catalytic converters used in oil refineries, etc.

\section{CONCLUSION}

The need for energy transition in a sustainable development context demonstrates the importance of switching to fully electric vehicles (VEEs) like BEVs (Battery electric vehicles) and FCEVs (Fuel cell electric vehicles), which are 100\% electric versions. This requires changes in the production and use of energy in the transportation industry involving clean technologies. In this context, opposing these two technologies would not be the best approach because both can contribute to this mission in a diverse and complementary way. So far, each of the technologies is facing the following common challenges that will need to be addressed: the availability of material reserves, access and the cost of extracting raw materials to supply these devices and systems; the environmental cost of their production and use; the cost of their operating infrastructure (among other things, charging stations for BEVs [Battery electric vehicles] and hydrogen stations for FCEVs [Fuel cell electric vehicles]). The type of energy source that will be transformed to ensure their production, use and recycling, the diversification of the technology of these vehicles and our moderation in their use will lead to less "stress" on the availability and accessibility of the materials used in these technologies. This could also reduce the impacts on the extraction process of these materials and their effects on the environment and health. Uncertainties about energy development choices in each country over the next few years and countries' choices to support long-term transportation based on FEVs (Fully Electric Vehicles) can have unpredictable consequences. Keeping both technologies is therefore necessary and, eventually, their maturity will lead to appropriate choices by developers and users.

\section{REFERENCES}

[1] Key World Energy statistics 2019, IEA, February, 2020.

[2] Global EV Outlook 2020, IEA, June 2020.

[3] https://auto.howstuffworks.com/fuelefficiency/hybrid-technology/history-of-electriccars2.htm, consulted on August, 17, 2020

[4] https://www.caaquebec.com/fr/sur-laroute/conseils/outils-et-references/couts-dutilisationdes-vehicules/, consulted on August, 18, 2020

[5] https://tech.hyundaimotorgroup.com/article/thefuture-lies-in-ev-or-fcev/, consulted on August, 19, 2020

[6] https://cleantechnica.com/2020/02/19/bloombergnef -lithium-ion-battery-cell-densities-have-almosttripled-since-2010/, consulted on August, 18, 2020

[7] https://fuelcellsworks.com/news/in-2019-83-newhydrogen-refuelling-stations-worldwide/, consulted on August, 19, 2020

[8] https://www.statista.com/statistics/270603/worldwid e-number-of-hybrid-and-electric-vehicles-since2009/, consulted on August, 20, 2020

[9] https://www.virta.global/global-electric-vehiclemarket, , consulted on August, 19, 2020

[10] https://www.electrive.com/2020/02/26/zswanalysis-shows-global-number-of-evs-at-7-9million/, , consulted on August, 17, 2020

[11] https://www.salon.com/2019/06/17/lithium-miningfor-green-electric-cars-is-leaving-a-stain-on-theplanet/, , consulted on August, 20, 2020

[12] https://www.researchandmarkets.com/reports/48457 10/automotive-fuel-cell-system-market-analysis

[13] https://pubs.usgs.gov/periodicals/mcs2020/mcs2020 -platinum.pdf, consulted on August, 17, 2020

[14] https://www.lelementarium.fr/product/platinoides/, , consulted on August, 17, 2020

[15] Critical Issues in Transportation 2019: https://www.nap.edu/resource/25314/criticalissues/, , consulted on August, 31, 2020 